\title{
Stagflation, the Labor Market Impact, and the Poverty Puzzle in Pakistan: A Preliminary Analysis
}

\section{Rashid Amjad ${ }^{*}$}

\begin{abstract}
This article discusses the impact of the current stagflation in Pakistan on the labor market and poverty. The paper presents a preliminary explanation of why the labor market and poverty impact of the current stagflation may be far smaller than projected in recent studies, especially for the rural economy. The main conclusions that emerge are that (1) The overwhelming expected negative impact of low economic growth, high double-digit inflation, and crippling energy shortages on poverty and the labor market appear to have been cushioned by the large increase in remittances, rising wages in agriculture and services, and social safety nets; (2) there is, however, no reason for complacency since over 20 million people live in absolute poverty and that the economy remains in deep stagflation, (3) the PSLM (HIES) 2010/11 data should be made publicly available so that it can be subject to more critical analysis and (4) studies on poverty should be based on a close integration of macro-sectoral-micro-factors to fully capture the underlying "poverty dynamics."
\end{abstract}

Keywords: Macro-dynamics, economic growth, cycles, Pakistan.

JEL classification: P46, F43.

\section{Introduction}

Over most of the last 65 years, Pakistan has grown in stop-go cycles. The macro-dynamics underlying these cycles have been subject to close examination. ${ }^{1}$ More recently, attention has focused on explaining a new phenomenon-a prolonged stagnation over the last five years, 200712, characterized by low economic growth and high double-digit inflation-and on the measures attempting to overcome it, albeit with little success so far (see Amjad, Din, \& Qayyum, 2011).

\footnotetext{
* Vice Chancellor, Pakistan Institute of Development Economics, Pakistan.

${ }^{1}$ For an exhaustive review, see McCartney (2011). See also the Appendix for differences between more recent stagflation and past stop-go cycles post-1980.
} 
Understandably, studies analyzing the expected impact of this prolonged stagflation projected a sharp increase in both unemployment and poverty. These studies have drawn on the results of earlier studies that had estimated the impact of economic growth and inflation (mainly food inflation) on unemployment and poverty. However, little attention has been paid to the specific features and dynamics of the current stagflation, which may be significantly different from the conditions prevailing in the time periods covered in the earlier studies. More importantly, the estimated coefficients and elasticity of the relationship between poverty and economic growth and other variables derived in the earlier studies could significantly change and, hence, distort the results of more recent studies.

It is not, therefore, surprising that, when data began to emerge on recent trends in unemployment and poverty, which in most cases was quite contrary to what recent studies had predicted, these studies were met with considerable disbelief and finger pointing. ${ }^{2}$

This article wants to mark a beginning of a serious debate on the impact of the current stagflation on the labor market and poverty, drawing on not just macroeconomic developments that have been seen as major explanatory variables in the current debate, but combining them with a more in-depth understanding of the macro-sectoral-micro- (mainly labor market) dynamics of the current situation. ${ }^{3}$

Such an approach is also dictated by Pakistan's historical experience, where the relationship between growth and poverty has not been straightforward. It has witnessed periods of high growth with little decline in poverty, as in the 1960s. By contrast, in the 1970s low economic growth was accompanied by a fall in poverty. Post-1980, however, periods of high growth have been positively related to a decline in poverty as in the 1980s and 2001-07, while low economic growth in the 1990s witnessed a rise in poverty. Interestingly, when growth declined significantly in $2007 / 08$, poverty continued to decline and unemployment continued to fall (see Naseem, 2012).

2 Indeed this has been true not just for the recent debate on poverty trends, but going back to changes in poverty levels since the 1960s. For an excellent review of past studies and debates, see Naseem (2012).

${ }^{3}$ See Bourguignon, Bussolo, and da Silva (2008) who present macro-micro evaluation techniques and tools to analyze the impact of macroeconomic policies on poverty and income distribution. As their introduction states, "In fact, the application of variants of a single modeling framework-a macro model linked with household level micro-is the unifying methodological theme of this volume." Although the current study does not carry out any modeling exercise, this is clearly a field open for further study. 
The remaining article is divided into five main sections. Section 2 presents a brief review of studies projecting the impact of the current stagflation on unemployment and poverty. Section 3 then presents the evidence based on recent data on movements of key labor market and poverty-related variables. Section 4 presents the results of previous studies that have estimated the impact of key economic variables on poverty and on which recent studies have mainly relied. Section 5 attempts a preliminary explanation of why the labor market and poverty impact of the current stagflation could have been far smaller than projected in recent studies, especially for the rural economy. Here, we explore the macrosectoral-micro dynamics of the current stagflation. The concluding section summarizes our main findings and makes some suggestions on how best to carry forward this debate.

\section{A Review of Selected Studies on the Impact of the Economic Slowdown and Inflation on Unemployment and Poverty}

("He who has not sinned throw the first stone"!)

The results of four important studies on Pakistan are discussed here, together with the results of a World Bank (2012) update on global estimates of poverty. As we shall see, all four studies projected a sharp increase in poverty post-2008. The World Bank study, in contrast, presented preliminary global updated estimates for 2010, which indicated that poverty in developing countries based on a smaller sample (which probably did not include Pakistan) continued to fall, as it had done over 2005-08.

\subsection{The Panel of Economists: Interim Report on Economic Stabilization with a Human Face ${ }^{4}$}

The Panel of Economists set up by the Planning Commission in September 2008 consisted of eminent economists who were to recommend measures to overcome the economic crisis resulting from unsustainable current account and fiscal deficit. These deficits had reached 8 and 9 percent of GDP, respectively, as a result of the unprecedented increase in oil and food prices accentuated by a policy of "inaction and neglect" adopted by the last government. The Panel's recommended stabilization measures to restore macro-stability and avoid default were accepted by the government, which saw them as an endorsement of the standby-

\footnotetext{
4 The author was a member/convener of this panel and shared the views expressed in its report.
} 
arrangement it had negotiated with the International Monetary Fund (IMF) to stabilize the economy (see Pakistan, Planning Commission, 2008). The Panel, as indeed did the IMF, strongly advocated adopting cost-effective social safety nets to help cushion the negative impact of stabilization on the poor and the vulnerable-hence, stabilization with a "human face."

The Panel had undertaken a simulation exercise to determine the impact of stabilization measures on key economic variables, based on an abridged version of the integrated social policy and macroeconomic model (SPMM) developed by the Social Policy and Development Centre and the Planning Commission's consistency model-macroeconomic framework. The main results in relation to unemployment and poverty were as follows.

1. The unemployment level would increase further in 2008/09, due to the deepening of the economic downturn, and the unemployment rate would increase cumulatively by 3 percentage points over 2008/09 and 2009/10, reaching a level of well over 8 percent. These estimates were based on an employment elasticity of 0.45 , based on past trends applied to projected economic growth over these years.

2. The proportion of those below the poverty line would increase by 3.5 percentage points in 2007/08 (mainly due to the explosion in food prices), 2.7 percentage points in 2008/09, and 2.0 percentage points in 2009/10.

3. Based on informed judgment, as the Panel's report put it, combining the inflation and unemployment effects would add 6 percentage points to poverty incidence in 2004/05, raising the poverty level to 35 percent in 2008/09 if the level in 2004/05 was taken as 29 percent (or to 31 percent if the 2004/05 level was taken as 25 percent). This would, it claimed, translate into an additional 15 million people falling below the poverty line by 2008/09.

It must be said that the Panel was aware of the shortcomings of the exercise carried out-mainly the lack of more recent data, which precluded a more systematic and rigorous exercise being undertaken. But, clearly, the message was that both unemployment and poverty would increase as a result of stabilization, the global financial crisis and the resulting global recession accentuated by a sharp increase in prices as subsidies were cut back to restore the macro-balance. 


\subsection{Institute of Public Policy: Annual Reports on the State of the Economy}

The Institute of Public Policy (IPP)'s first annual report, State of the Economy (2008) was released just before the budget in June 2008 (as was to be done in subsequent years), soon after the newly elected government had taken office earlier in March. The report claimed that poverty had risen substantially to 33.8 percent in 2007/08 due to food inflation and the slowdown in economic growth, with the level increasing from 29.2 percent in 2004/05 (taken as the base year using the World Bank's re-estimated poverty estimates compared to the 25.2 percent claimed by the government, using the same dataset for 2004/05.)

The IPP report projected a continuing rise in poverty (see Table 1) if the increase in food prices and low growth was to persist, rising to as high as 43 percent of the population or 80 million people falling below the poverty line by $2011 / 12$.

Table 1: IPP estimates of poverty incidence, 1999-2012

\begin{tabular}{lccc}
\hline & Headcount ratio & \multicolumn{2}{c}{ Impact of food inflation } \\
\cline { 2 - 4 } Year & $\begin{array}{c}\text { World Bank } \\
\text { estimates }(\%)\end{array}$ & $\begin{array}{c}\text { Headcount ratio } \\
(\%)\end{array}$ & $\begin{array}{c}\text { Number of poor } \\
(\text { millions) }\end{array}$ \\
\hline $1998 / 99$ & 30.0 & 30.00 & 40.35 \\
$2001 / 02$ & 34.4 & 34.40 & 50.21 \\
$2004 / 05$ & 29.2 & 29.20 & 45.48 \\
$2005 / 06$ & & 28.68 & 45.74 \\
$2006 / 07$ & & 29.47 & 48.12 \\
$2007 / 08$ & & 33.81 & 56.55 \\
$2008 / 09$ & & 36.11 & 61.84 \\
$2009 / 10$ & & 38.41 & 67.35 \\
$2010 / 11$ & & 40.70 & 73.10 \\
$2011 / 12$ & & 43.01 & 79.08 \\
\hline
\end{tabular}

Source: IPP. (2008). State of the economy, Table 4.7.

The report does not clearly spell out the detailed methodology adopted to project poverty for the period 2005/06 to 2011/12, but states that it was based on the coefficients of the elasticity of poverty with respect to food inflation, adjusted for growth in per capita income, estimated by Akhtar and Ahmed (1999). These coefficients must then have been applied to the projected growth and inflation figures used in the report. 
The IPP's subsequent three annual reports continued to claim a rising and high level of poverty, but it would appear that no new exercise was undertaken, and that these were drawn from the 2008 report as economic conditions had not changed and high inflation and low growth persisted. In its latest annual report (2012), the IPP turns its attention from poverty to worsening income distribution, based on a comparison of the latest Household Integrated Economic Survey (HIES) for 2010/11 and 2007/08 data (as reported in the Pakistan Economic Survey for 2011). However, the reports presents no new estimates of poverty, presumably because the raw HIES 2010/11 data had not been released. The report expresses its concern about the conditions of the lower-income group as follows:

Even though we believe that the HIES surveys understate income inequality, it is noteworthy that they report that inequality has continued to increase during the last three years. Overall, the lowest two quintiles of household have suffered a drop in their real incomes, while significant increases have been recorded in the case of upper-income households. This also implies that the incidence of poverty have increased during the last three years (italics added) (IPP, 2012, p. 32).

\subsection{Asian Development Bank: Food Poverty and Inflation in Developing Asia: Is Poverty Reduction Coming to an End? (2008)}

As food inflation rose in response to the steep rise in oil and commodity prices in 2007/08, international agencies including the Food and Agriculture Organization, the World Bank, and the Asian Development Bank (ADB) all warned of an impending crisis due to large expected increases in poverty and malnutrition, given that the poor spend a large proportion of their income on food grains. Many of these agencies also released data on the numbers that would fall into poverty and suffer malnutrition.

Somewhat dramatically, the ADB (2008) questioned whether the poverty reduction achieved in the recent past was coming to an end with rising food inflation. Comparing the impact of the rise in food prices on poverty in the Philippines and Pakistan, the ADB showed that the impact on the latter was much larger (almost three times) due to its lower per capita income, thus illustrating the vulnerability of the low-income developing countries. Applying these estimates to Pakistan, where food inflation increased by almost 80 percent in the four years post-2007/08, 
would imply that the number of people in poverty more than doubled by 2010/11 - a figure near that estimated by the IPP. 5

Table 2: Changes in number of poor (millions) with increase in food prices

\begin{tabular}{lccc}
\hline Country & $\mathbf{1 0 \%}$ & $\mathbf{2 0 \%}$ & $\mathbf{3 0 \%}$ \\
\hline Philippines & 2.72 & 5.65 & 8.87 \\
Pakistan & 7.05 & 14.67 & 21.96 \\
\hline
\end{tabular}

Note: To estimate the number of additional poor, national poverty lines were used. These estimates are concerned only with the price effect on consumers, i.e., they do not take into account the impact of prices changes on producers.

Source: ADB. (2008). Food prices and inflation in developing Asia: Is poverty reduction coming to an end?

\subsection{ADB: Global Food Price Inflation and Developing Asia (2011)}

With the re-emergence of a spike in global food prices in 2011, which had increased by more than 30 percent year on year, the ADB (2011) undertook a fresh exercise to estimate its impact on poverty. The results for Pakistan projected a 2.2 percentage point increase in the percentage of the poor for a 10 percent increase in food prices, and an increase of 3.47 million people in the number of the poor. It is interesting to note that these estimates are almost half of the earlier estimates, and bring out the sensitivity of such analysis to the methodology used. ${ }^{6}$

While the government still did not officially acknowledge the poverty estimates for 2007/08, it is interesting that the Pakistan Economic Survey for 2010/11 cites the ADB (2011) study in detail. The latter's numbers are used to state that, if they were true, poverty would increase by almost 50 percent, given a food inflation rate of around 70 percent in the preceding three years. Clearly, the government was taking international agencies' estimates seriously.

\subsection{World Bank: Global Poverty Update (2012)}

Like the ADB, the World Bank had also drawn attention through press and other statements to the vulnerability of developing countries to

5 With an 80 percent increase in food inflation between 2007 and 2012, the ADB's estimates would imply an increase of 56 million people in poverty.

${ }^{6}$ These estimates were derived using the price elasticity of poverty, which was estimated for both the headcount ratio and poverty gap ratio (see ADB, 2011). 
the spike in food prices, emphasizing that extreme poverty levels would, in consequence, substantially increase post-2008. It therefore came as a surprise to many when the World Bank announced that its preliminary estimates for 2010 indicated that poverty had continued to fall despite the global economic crisis and other shocks, and that the first Millennium Development Goal had been met. As for the earlier ones for 2005-08, these estimates were based on a poverty line of USD 1.25 a day, but were drawn from a smaller sample of developing countries than for the 2005-08 estimates (World Bank, 2012).

It may be important to note here that these were perhaps the first estimates by an international agency to suggest that poverty levels had not been impacted to the extent that many of them had predicted as a result of the global economic crisis and food inflation. However, these results caught little global attention and indeed have not been cited in the recent poverty debate in Pakistan.

\section{The Impact of Stagflation on the Labor Market and Poverty: What Actually Happened (or What the Data Suggests Happened)}

\subsection{Labor Market Developments}

Let us start by examining what happened in the labor market. The Panel of Economists had projected a sharp increase in unemployment, and though the exact increase projected varies somewhat in different sections of the report, the broad conclusion was that it would increase from around 6 percent in 2006/07 to well over 8 percent by 2009/10, adding almost 2 million to the unemployed (see Pakistan, Planning Commission, 2008).

The more recent data based on the Pakistan government's Labour Force Surveys shows that, while unemployment did go up, the increase was far smaller than what the Panel had projected. As Figure 1 shows, unemployment increased from around 5 percent in 2007/08 to 6 percent in 2010/11, not to well over 8 percent as the Panel's projections had implied. Interestingly, unemployment continued to decline between 2006/07 and $2007 / 08$, while the Panel (and other analysts) had expected an increase due to the slowdown in economic growth. (Indeed, other studies-including that by the World Bank-have used this decline to justify the decrease shown in the $2007 / 08$ poverty estimates.)

This study further explores the impact of the economic slowdown on the labor market by examining the behavior of real wages during this period. According to our estimates, the real wages of agricultural workers 
showed a substantial increase between 2007/08 and 2009/10. These estimates are based on wage data given in the annual reports of the Agriculture Policy Institute (API). The findings are supported by preliminary studies at the Pakistan Institute of Development Economics (PIDE), which, based on Labour Force Survey data, also show an increase in real wages in agriculture during these years, though the suggested increase is smaller than that implied by the API data. ${ }^{7}$

\section{Figure 1: GDP growth, unemployment rate, and real wages of agricultural and construction workers}

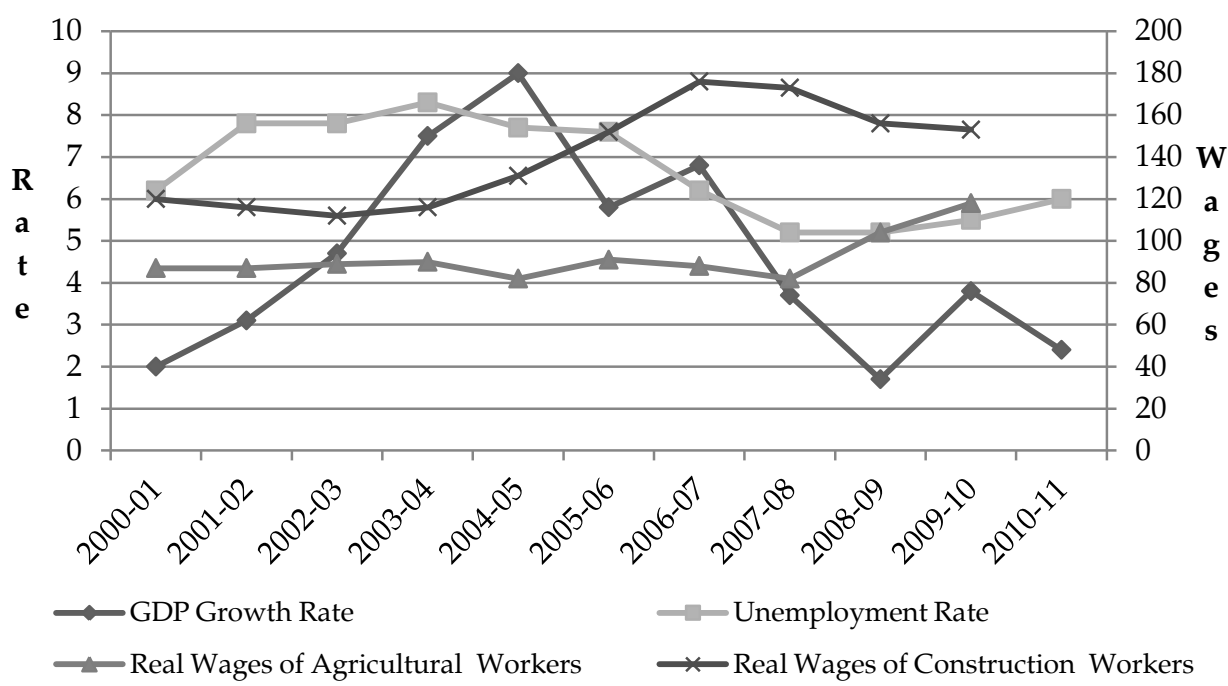

Sources: Pakistan Economic Survey (2001-2011); Labour Force Survey (2001-2011); Agriculture Policy Institute (2001-2011), Support price policy for wheat: Annual report.

For urban areas, the daily real wages of construction workers show a decline of around 15 percent between 2007/08 and 2009/10 in contrast to rural agricultural workers. In the services sector, which reflects more urban than rural, PIDE's preliminary estimates (based on Labour Force Survey data) show an increase.

In examining these labor markets developments, it is important to bear in mind that unemployment rates may not fully capture the state of the labor market-in the absence of any effective or comprehensive social safety nets, most people in developing countries have to work for a living.

7 I am grateful to Dr M. Irfan for carrying out this exercise based on the Labor Force Survey data available at PIDE. 
Therefore, in the context of developing countries, it is important to interpret unemployment as an indicator of the labor market along with other variables - such as what is happening to real wages - to better gauge the extent to which the labor market might have slackened or tightened. A similar problem arises with elasticity-of-employment estimates-being the reverse of labor productivity, they may show an increase as people move from higher-productivity to lower-productivity jobs, and fail to capture the slackening in the labor market.

\subsection{Recent Estimates of Poverty}

It is in predicting what would happen to poverty in the face of a prolonged stagflation that-at least on the basis of the latest Pakistan Social and Living Standards Measurement Survey (PSLM/HIES) 2010/11 poverty estimates-the studies reviewed, and indeed many analysts, appear to have really got it wrong.

The Arif Commission, set up by the Planning Commission to calculate the level of poverty, use the same 2,350 caloric poverty line as for earlier years to estimate a further decline in poverty from 17.2 percent in $2007 / 08$ to 12.4 percent in 2010/11, based on the PSLM (HIES) data for the latter year. ${ }^{8}$ Its results also suggest that poverty has declined in both urban and rural areas, with the former falling to just over 7 percent and the latter at around 16 percent.

The second important set of poverty estimates to have recently emerged are from PIDE's Pakistan Panel Household Survey (PPHS) conducted in 2010. These results are not strictly comparable with the PSLM (HIES) data as the PPHS panel is slightly biased toward poorer districts in Pakistan. Moreover, the PPHS only covers rural poverty till 2004 and only the Punjab and Sindh provinces in that year. Nonetheless, the results are revealing. Based on the same poverty line of 2,350 calories, the data shows that, while rural poverty did increase in Punjab and Sindh between 2004 and 2010, it did so marginally - from around 24 to 27 percent. Rural poverty for 2010 for all provinces is estimated at 22.4 percent (Arif \& Farooq, 2012).

These findings on poverty based on the two most recent surveys conducted in 2010 and 2010/11 clearly indicate that there was, at best, a slight increase in poverty; indeed, there could have even been a

8 See Khan (2012, May 8). These results have been frequently cited in the press and are now generally accepted as reflecting the results derived by the Arif Commission. 
significant decline. These results are quite contrary to what the four studies we have analyzed had projected. The only exception to these results is the World Bank global estimates for developing countries, which had projected a continuation of the declining trend in poverty witnessed during 2005-08 to 2010. However, the World Bank's figures did not, in all probability, cover Pakistan.

\section{Factors Impacting Poverty in Pakistan: Results of Selected Past Studies}

In examining these recent results on poverty and coming up with a possible explanation for how this could have happened, let us briefly review the results of three important studies that identify explanatory variables and their coefficients in determining poverty movements in Pakistan. (For a more detailed review, see Naseem, 2012.)

Amjad and Kemal (1997) cover the period between 1963/64 and $1992 / 93$, and identify real per capita income (-1.01), remittances per capita $(-0.23)$, and real wages $(-0.22)$ as significant variables. Interestingly, they do not find inflation to be significant. ${ }^{9}$ Akhtar and Ahmed (1999) extend Amjad and Kemal's study, mainly by increasing the number of observations for poverty by extrapolating poverty figures for years not available. The important variables they identify are real per capita income $(-1.87)$, remittances per capita $(-0.09)$, increases in food prices $(0.52)$, the human capital index $(-0.80)$, and decline in unemployment $(-0.11)$.

A key variable that is not incorporated by the studies analyzed in Section 2 is remittances, which, we have seen, is identified as a significant variable in explaining the poverty decline in Pakistan (Akhtar \& Ahmed, 1999; Amjad \& Kemal, 1997). Remittances have increased by just over USD 1 billion in 2000/01 to nearly USD 13 billion in 2011/12 (Pakistan, Ministry of Finance, 2012). A recent study by Amjad, Arif, and Irfan (2012) identifies a rise in the number of Pakistanis abroad and higher-skilled migrants as important factors for this increase (besides the tightening of laws to reduce money laundering, i.e., sending remittances through unofficial or "hawala" channels). The study also suggests that these remittances are from not just Pakistani workers abroad but from the entire Pakistani diaspora, which is estimated at around 8 million.

In the context of the impact of remittances on poverty, Amjad's (2010) study for the recent period is important because it shows that this

${ }^{9}$ Figures in parentheses are elasticities. 
impact depends critically on two factors. The first is whether remittances are sent through official or unofficial channels, with the former having a far greater impact on the economy and, through it, on poverty, compared to far smaller impact of unofficial flows, which represent transfer payments within Pakistan rather than actual inflows into the country. The second factor concerns the sender of the remittances, with the impact on poverty being much greater if remittances are sent by semi-skilled and unskilled workers to their families back home compared to those sent by professionals or middle- to high-income earners or by those permanently settled abroad. Siddiqui (2011) also shows that, in Pakistan's case, the share of remittances from the Middle East has had the highest negative impact on poverty while remittances from industrialized developed countries appear to have had little or no impact on poverty.

More recently, Arif and Farooq (2012) have analyzed the results of the three rounds of the PIDE/PPHS in rural areas conducted in 2001, 2004, and 2010. They also offer some very important insights into poverty dynamics in Pakistan. According to their analysis, only 9 percent of Pakistan's rural population lives in chronic poverty, while almost 50 percent move in and out of poverty, showing their extreme vulnerability to economic shocks such as a rise in food prices, illness, and natural disasters such as floods or earthquakes. Arif and Farooq also identify land ownership, number of livestock, education levels, and family size as important explanatory variables determining those who live in poverty and those who do not. Their preliminary study has not yet explored factors such as remittances (though data is available) and their impact will be discussed in later reports.

Two important conclusions emerge from this brief review. The first is that, besides economic growth and food inflation, there are other important variables-especially remittances and changes in the labor market (the unemployment rate, real wages) — that impact poverty. The second is that measuring this impact in terms of elasticity coefficients, i.e., the elasticity of poverty with respect to these variables, is sensitive to both the time periods covered as well as the methodology used.

\section{Toward Explaining the Impact of Stagflation on Poverty and the Labor Market}

In the face of both national and regional studies that strongly advocated that the slowdown in economic growth and high food inflation would lead to a very large increase in poverty (as discussed in Section 2), 
can there be any plausible defense of the contrary results emerging from the recent surveys put forward in Section 4 ?

A simple option would be to say that the data is unreliable or, worse, doctored, and put an end to the debate.

Alternatively, can one probe deeper into the dynamics of the current stagflation and explore how the macro-developments worked themselves through the economy and impacted people's lives? Were some sectors of the economy-especially those in which the poor are concentratedshielded from the economic slowdown? Was the rural economy doing better than the urban economy? Was the informal economy still managing to grow while the formal economy bore the brunt of the economic slowdown? Did remittances protect the poor from high inflation? Were the government's social protection initiatives, e.g., the Benazir Income Support Programme (BISP), and the large increases in public expenditure on social protection able to provide an effective safety net that protected people from falling into poverty? Is Pakistan a "two-speed economy"?

These are important questions that analysts have raised in the context of the continuing stagflation and the so-called "resilience" of the Pakistan economy in the face of a host of adversities. Clearly, it is not possible to do justice to all these issues in this article. Nonetheless, even a somewhat partial and preliminary analysis can help find important clues that might well provide some justification for the recent results on poverty.

Let us first, however, put the data issue to rest.

\subsection{The Poverty Data}

An important premise of this paper is that very little is gained by taking the view that the data is not accurate. Most data in developing countries, whether on poverty or national income, is not, being at best robust and reflecting broad changes rather than very accurately capturing them. To suggest that the data has been tampered with is also not very helpful, for again there is no reason to believe that one government is less or more honest than the other. In any case, the data results of the PSLM (HIES) 2010/11 were derived by a team headed by an independent expert on poverty. If economists were to discard data on the basis of these two explanations, they would not have any time-series data or, for that matter, any data with which to work. 
This view does not preclude the possibility that the methodology used to work out a consistent poverty line could be subject to debate and, indeed, controversy, as has happened in the past. This issue is important, given the extreme sensitivity of poverty estimates to the poverty line and that a large number of households are clustered just below or above the poverty line.

\subsubsection{The Rural vs. Urban Economy}

The agriculture sector grew at only around 2.5 percent on average over 2007-12, with wide fluctuations resulting from weather conditions and floods. This would mean that there was little growth in productivity. However, the rural economy received a strong stimulus when the new democratic government doubled the procurement price of wheat from PKR $450 / 40 \mathrm{~kg}$ to PKR 950/40 $\mathrm{kg}$ during the course of 2008/09. Wheat is the major crop grown during the winter months (the "rabi" season), and though fertilizer and energy prices also increased, farmers' profits received a major boost. The support price of rice was also increased to reflect rising world prices. The prices of other crops also rose. On the whole, these increases led to a major shift in the domestic terms of trade in favor of agriculture.

This, together with the healthy growth of the livestock sector, which now contributes just over 50 percent of value-added to agriculture, led to a spurt in consumer spending. This was reflected in high growth in rural demand for goods such as food and beverages and for consumer durables, including motor vehicles and motorcycles. ${ }^{10}$

Was this boom restricted to large and medium-size farmers and food merchants, while small farmers and landless labor-who account for 30 percent of the rural labor force and who are net buyers of food grains-lose out? The data on agricultural workers' real wages does not support this viewpoint as these increased substantially (see Section 4). This makes sense for, clearly, farm laborers were aware of the price hike and, even if no longer paid mostly in kind, appear to have been able to bargain for a higher wage.

\footnotetext{
10 To quote from the Pakistan Economic Survey for 2010/11 (Pakistan, Ministry of Finance, 2011, p. 36) describing economic changes during that year: "Initial spurt in large scale manufacturing was supported by enormous raise in and allowances of public sector employees, and huge transfer of resources to rural areas owing to higher prices of agriculture. Moreover, significant rise in worker's remittances as well as public/private transfers to the flood affected areas has strongly impacted on the consumer demand for consumer durables [sic]."
} 
In contrast, the urban economy was, clearly, badly hit by the global recession and energy shortages. This was especially true of manufacturing, where not just large- and medium-scale industry but also the small-scale sector, which could not afford captive power, was badly affected. The services sector, however, appears to have shown signs of healthy growth, and here remittances may well have played an important part. Real wages in services, which is more urban than rural, increased during this period. A substantial increase in the wages of public sector employees-raised by 50 percent in July 2010-and increases of about half this amount in other years, would have provided protection against inflation.

The large cuts in public sector expenditures as part of the stabilization program adversely affected the construction sector. This, together with a slump in private sector housing, is reflected in the decline construction workers' wages.

\subsubsection{The Formal vs. Informal Economy}

The State Bank of Pakistan's (2012) ${ }^{11}$ view is that, while the formal sector was badly hit as a result of the global recession and power outages, the informal economy-which contributes about one third in value-added to the overall urban economy but employs nearly 70 percent of the urban labor force-remained resilient, growing apparently by its "bootstraps." This view ignores the linkages between the formal and informal economies; if the former had been badly hit, it is difficult to see the informal economy growing simply on its own. Again, remittances could counter this argument.

To sum up, it would appear that there were sectors that managed to grow despite the overall slowdown in economic growth. There were two major factors responsible for this. The first was the stimulus to the rural economy, spurred by a large increase in the prices of major food crops and steady growth in the nonfarm sector, which led to a growth in demand for selected manufactures and the growth of the services sector. The second factor was the massive increase in remittances, which doubled during these five years to over USD 13 billion in 2011/12, and raised consumption demand as little of it flowed into investment due to economic uncertainty and the deteriorating law-and-order situation. This view is supported by the fact that consumption levels increased throughout this period, while

11 To quote, "There is a growing sense that Pakistan's undocumented economy (the informal economy) is vibrant. In effect there seems to be a disconnect" (State Bank of Pakistan, 2012, p. 5). 
investment bore the brunt of low growth, falling from nearly 20 percent of GDP to around 11 percent during 2007-12 (see Amjad et al., 2011).

\subsection{Movement of Key Variables Impacting Poverty, 2007-12}

A more rigorous, econometric analysis attempting to explain the decline in poverty during the last five years could establish whether the factors that impact increasing poverty outweighed those that lead to a decline in poverty.

While we have not undertaken such an analysis, we examine the movement of key variables that may have been important in impacting poverty, and then draw a more tentative conclusion, i.e., what this suggests in terms of an increase or fall in poverty levels during this period.

- Per capita income growth was low in this period, on average, around 2.5 percent, but still slightly higher than the growth in population at 2.1 percent per annum. Its overall impact could, therefore, be taken at best as neutral.

- Food inflation increased by nearly 80 percent over these five years, and is thus rightly identified as the most important factor that would have led to a significant increase in poverty. As per the ADB's (2008) projections, this could have doubled poverty to nearer 35 or 40 percent of the population, as indeed the IPP's projections also suggest.

- Real wages increased for agricultural workers but declined for the construction sector; wages overall increased in the services sector. Given that poverty is higher in rural areas and that the landless are the most vulnerable overall, these movements could have led to a decline in poverty.

- Remittances per capita showed a continuing phenomenal increase between 2007 and 2012, doubling in volume to just over USD 13 billion in 2011/12. This massive increase would have had a strong impact on reducing poverty. The impact would have been greater during this period as Amjad et al. (in press) show that there has been (i) a significant shift in remittances toward rural areas, (ii) a large increase in the number of Pakistani workers going abroad, and (iii) an increase in remittances coming through formal rather than informal channels.

- The human capital index, though still low, has improved slightly in recent years, especially in relation to the youth population (15-24 years), implying that it had a marginal impact on reducing poverty. 
- Unemployment increased by around one percentage point and would have led to a rise in poverty, but this impact may have been negated to some extent by rising real wages.

- There has been a very significant increase in both federal and provincial expenditures on measures to protect the poor through safety nets/social protection. At the federal level these increased from around PKR 10 billion in 2007/08 to PKR 80 billion in subsequent years. The major increase was direct income support to the female household head under the BISP, which was to cover 5 million households. Even accounting for shortfalls in coverage in earlier years and flaws in targeting the really poor and vulnerable, these expenditures would have significantly helped cushion the impact of the increase in food inflation on the poor.

If one were now to apply the elasticities of each of these variables with respect to poverty as estimated in earlier studies and other developments specific to this period, there is reason to believe that the negative factors were outweighed by the positive factors and that poverty could well have declined. In any case, this analysis clearly establishes that even if there was an increase, it was certainly not as high as earlier studies have claimed.

In drawing these still tentative conclusions, one needs to keep in mind that Pakistan is not an exception in being able to cushion the impact on poverty of the unprecedented increase in oil and commodity prices and ensuing global recession. The World Bank's global estimates of poverty cited earlier also point in the same direction, though clearly Pakistan's economy has fared much worse than most developing economies, especially compared to its South Asian neighbors.

The analysis clearly shows, however, that the methodology applied by the earlier studies was seriously flawed. To merely relate food inflation to poverty was to ignore the many other important developments taking place in the economy, which both cushion and mitigate its impact. There is an inherent dynamic in all economies where different actors, including the state, adjust in different ways to a price or other shock to the economy. Analyzing this macro-sectoral-micro-interaction provides a far better understanding of what is happening to poverty in Pakistan than just identifying one variable, however important it may be, and coming up with sensational results.

\section{Conclusions}

The main conclusions that emerge from this study are given below. 
- The overwhelming expected negative impact of low economic growth, high double-digit inflation, and crippling energy shortages on poverty and the labor market appear to have been cushioned by the large increase in remittances, rising wages in agriculture and services, and social safety nets.

- There is, however, no reason for complacency and it should be kept in mind that, even today, over 20 million people live in absolute povertyless than PKR 1,750 per person per month or just over PKR 55 per day in $2010 / 11$ prices - and that the economy remains in deep stagflation.

- $\quad$ The PSLM (HIES) 2010/11 data should be made publicly available so that it can be subject to more critical analysis.

- Perhaps this article's most important message is that studies on poverty should be based on a close integration of macro-sectoral-micro-factors to fully capture the underlying "poverty dynamics" and begin with an "open mind" rather than the pre-conceived, fixed positions that appear to mark much of the public debate on poverty in recent months.

Even if these conclusions on poverty are indeed true, it is important to point out that the Pakistan economy has been very poorly managed in recent years, and it would be a big mistake to take solace in the fact that poverty did not increase in this period. 


\section{References}

Agriculture Policy Institute. (2001-2011). Support price policy for wheat: Annual report. Islamabad, Pakistan: Author.

Akhtar, S., \& Ahmed, M. (1999). Modeling poverty trends in Pakistan: Some additional empirical evidence (Research Report No. 27). Karachi, Pakistan: Social Policy and Development Centre.

Amjad, R. (2010). Remittances and poverty in Pakistan: A note. In L. Banerjee, A. Dasgupta, \& R. Islam (Eds.), Development, equity and poverty: Essays in honor of Azizur Rehman Khan. New Delhi, India: Macmillan.

Amjad, R., \& Kemal, A. R. (1997). Macroeconomic policies and their impact on poverty alleviation. Pakistan Development Review, 36(1), 39-68.

Amjad, R., Arif, G. M., \& Irfan, M. (2012). Preliminary study: Explaining the ten-fold increase in remittances to Pakistan 2001-2012. PIDE Working Paper, 2012:86, Islamabad, Pakistan: Pakistan Institute of Development Economics.

Amjad, R., Din, M., \& Qayyum, A. (2011). Pakistan: Breaking out of stagflation into sustained growth [Special edition]. Lahore Journal of Economics, 16, 13-30.

Arif, G. M., \& Farooq, S. (2012). Dynamics of rural poverty in Pakistan: Evidence from three waves of the panel survey. Islamabad, Pakistan: Pakistan Institute of Development Economics.

Asian Development Bank. (2008). Food prices and inflation in developing Asia: Is poverty reduction coming to an end? Manila, Philippines: Author.

Asian Development Bank. (2011). Global food price inflation and developing Asia. Manila, Philippines: Author.

Bourguignon, F., Bussolo, M., \& da Silvia, L. A. P. (Eds.). (2008). The impact of macroeconomic policies on poverty and income distribution: Macromicro evaluation techniques and tools. Washington, DC: World Bank.

Institute of Policy Studies. (2008). State of the economy: Challenges and opportunities. Lahore, Pakistan: Author. 
Institute of Policy Studies. (2009). State of the economy: Emerging from the crises. Lahore, Pakistan: Author.

Institute of Policy Studies. (2010). State of the economy: Pulling back from the abyss. Lahore, Pakistan: Author.

Institute of Policy Studies. (2011). State of the economy: Devolution in Pakistan. Lahore, Pakistan: Author.

Institute of Policy Studies. (2012). State of the economy: The Punjab story. Lahore, Pakistan: Author.

Khan, A. H. (2012, May 8). Poverty number revisited. The News.

McCartney, M. (2011). Pakistan: The political economy of growth, stagnation and the state, 1951-2009 (Routledge Studies in the Growth Economies of Asia). Abingdon, UK: Routledge.

Naseem, S. M. (2012). A review of studies on poverty in Pakistan: Origin, evolution, thematic content and future directions (History of PIDE Series 6). Islamabad, Pakistan: Pakistan Institute of Development Economics.

Pakistan, Federal Bureau of Statistics. (2001-2011). Labour force survey. Islamabad, Pakistan: Author.

Pakistan, Ministry of Finance. (1981-2011). Pakistan economic survey. Islamabad, Pakistan: Author.

Pakistan, Planning Commission. (2008). Report of the Panel of Economists: Interim report on economic stabilization with a human face. Islamabad, Pakistan: Author.

Siddiqui, R. (2011). Pakistan: Migration, remittances and development. In S. Kelegama (Ed.), Migration, remittances and development in South Asia. New Delhi, India: SAGE Publications.

State Bank of Pakistan. (2012). The state of Pakistan's economy: Third quarterly report 2011-12. Karachi: Pakistan: Author.

World Bank. (2012). An update to the World Bank's estimates of consumption poverty in the developing word. Retrieved from http:/ / siteresources.worldbank.org/INTPOVCALNET/Resources /Global_Poverty_Update_2012_02-29-12.pdf 


\section{Appendix}

Figure A1: Pakistan's macroeconomic performance, 1980/81 to 2011/12

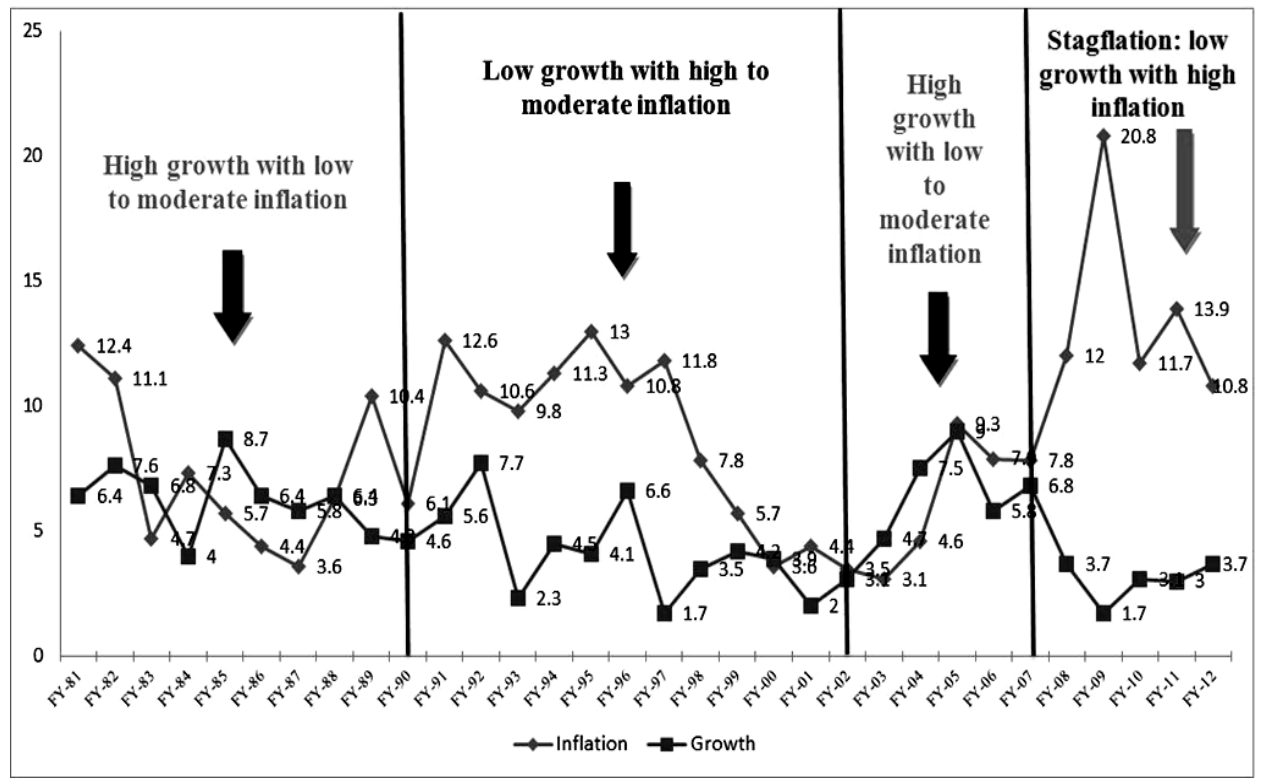

Source: Amjad, Din, and Qayyum (2011) (updated for 2011/12) and Pakistan Economic Survey. 